\title{
Grounding Malfunction
}

National Cancer Institute

\section{Source}

National Cancer Institute. Grounding Malfunction. NCI Thesaurus. Code C63125.

Problem associated with the inability to connect conductors of an electronic system for the purpose of controlling or impeding ground currents and voltages. 